\section{INTERNATIONAL BULLETIN OF BACTERIOLOGICAL NOMENCLATURE AND TAXONOMY \\ Volume 7 No. $1 \quad$ January 15,1957}

\title{
SOME PHYSIOLOGICAL AND TOXIGENIC PROPERTIES OF MEMBERS OF THE GENUS MICROCOCCUS IN RELATION TO TAXONOMY'
}

\author{
F. S. Thatcher, Ph. D., and W. Simon
}

The controversy over the validity of the existence of the two genera Micrococcus and Staphylococcus $(1,7,8,9,17)$ has been reopened recently. Resolution of the question had been attempted in the last edition of the Bergey Manual (5) by relegation of the genus Staphylococcus to a position of synonymy and definition of a series of species of Micrococcus to comprehend those of the two former genera closely in accord with the work of Hucker (12).

Apart from the question of the respective taxonomic legitimacy of retention of the two generic names (1), argument favouring recognition of the generic name Staphylococcus seems to centre upon a primary intent to reserve the generic name Staphylococcus for toxigenic forms of the non-chained Gram-positive micrococci. It has been suggested that the proposed genus be based upon the type species Staphylococcus aureus Rosenbach (for which the specific name pyogenes has also been preferred (8)) and for which culture F.D.A. 209 P (15) and, more recently, $S 33 \mathrm{R}_{4}$ (7) have each been proposed as the type-culture in the absence of an adequate record of a typeculture for the genus as originally propounded by Rosenbach (9).

A number of properties other than the "key" characteristics listed in the Bergey Manual have been described as being helpful aids in classification of this heterogeneous group, particularly with the objective of distinguishing between toxigenic (or pathogenic) and nontoxigenic forms. Gupta and Chakravarti (10) have recorded that pathogenic strains of the micrococci provide positive tests for both the methyl red and Voges Proskauer reactions while Evans, Bradford, and Niven (8) refer to "coagulase-positive staphylococci" as "one of the most homogeneous species of bacteria to be found in any genus" and recommend that this species be recognized as the type species for the genus Staphylococcus, a species said to be differentiable further by its property of the production of acid from glucose anaerobically in a defined complex medium.

\footnotetext{
${ }^{1} \mathrm{~A}$ contribution from the Microbiology Section of the Laboratories of the Food and Drug Directorate, Department of National Health and Welfare, Ottawa, Canada.
} 
Barber and Kuper (3) and Carrere and Roux (6) have of fered evidence to show that the production of phosphatase by micrococci may be used as an indicator of potential pathogenicity. Further, Cowan, Shaw and williams (7) have recently used an argument based on phage relationship to reverse a proposal of Shaw, Stitt and Cowan (15) that strain F.D.A. 209 P be considered as the neotype for a proposed species Staphylococcus aureus.

As a contribution to this question of nomenclature and in order to explore any possible relationship between the various properties of micrococci referred to above we have determined the following properties from a collection of 263 cultures of micrococci isolated from clinical sources and from foods: (a) their specific nomenclature in accord with the primary "key" properties to the species of the genus Micrococcus as listed in Bergey, viz.; formation of acid from mannitol, production of pigment, the use of ammonium phosphate as a sole source of nitrogen in a standard medium, the reduction of nitrate to nitrite, the liquefaction of gelatin, and litmusmilk reactions; (b) the methyl red and Voges Proskauer reactions; (c) anaerobic production of acid from glucose; (d) the production of coagulase and phosphatase; (e) the production of alpha and beta hemolysins and enterotoxin, ( $f$ ) the phage relationships of selected representative cultures.

\section{METHODS}

The test cultures used in this study, unless otherwise indicated, were originally selected from strains that produced acid on mannitol-salt agar (DifCo). The biochemical and cultural properties as referred to in Bergey (5) were determined for all cultures in accord with the Manual of Methods for Pure Culture Study (14). The production of acid from glucose under anaerobic conditions was determined using the medium and method described by Evans, Bradford and Niven (8) which involved use of a supernatant seal of "vaspar" to obtain anaerobiosis, and for corroboratory purposes, the same medium incubated under rigidly anaerobic conditions in Brewer jars in an atmosphere of hydrogen. Coagulase, phosphatase and the three specific toxins were determined as described by Thatcher and Simon (16). Phage-typing was carried out by standard methods at the National Phage-typing Centre, Ottawa, through 
the courtesy of Dr. E. T. Bynoe. The determination of toxins and phage reactions was limited to fifty cultures randomly selected from within groups of cultures demonstrated to have specific properties of coagulase and phosphatase production, viz., in the respective categories,,+++--+ and - for the two enzymes.

\section{RESULTS}

The data shown in Table 1 reports the distribution of 256 mannitol-positive and 7 mannitol-negative cultures within the species of Micrococcus (after Bergey), and lists their "key" reactions, the "MR-VP" reactions, their capacity to grow anaerobically and the $\mathrm{pH}$ of the culture medium after incubation for 10 days at room temperature under strictly anaerobic conditions. Ten species were recognized, though specific assignment in some instances could not be entirely free from equivocation. The species $\underline{M}$. pyogenes was represented by 173 cultures of which 82 were of the variety aureus and 91 the variety albus.

Representatives of seven species gave positive reactions for both the MR and VP tests, and representatives from all species were able to grow anaerobically with production of acid under the conditions defined by Evans, Bradford, and Niven (8). This latter result was duplicated when anaerobiosis was effected by the use of hydrogen in Brewer jars equipped with a sensitive $\mathrm{Eh}$ indicator (14) that remained in reduced condition throughout the incubation period.

Subsequent to completion of the foregoing experiment the authors learned that Breed (4) has recently endorsed the suggestion of Evans et al. (8) that the anaerobic production of acid from glucose should be a determinative criterion for the genus Staphylococcus. Because of the demonstration described above of the common occurrence of this property among species normally considered to be nonpathogenic, we have redetermined the production of acid aerobically and under the two conditions of anaeroblosis previously described from all cultures used in this study. Resultant $\mathrm{pH}$ values are expressed in Table 2. The original findings are confirmed.

Table 3 reports the distribution of cultures within each species based on their capacity to produce coagulase and phosphatase. The only species able to produce both enzymes 
TABLE ।

Determinative Reactions of Representatives of Various Microcaccus Species.

$$
\begin{aligned}
& z \\
& \mapsto \\
& \curvearrowleft \\
& \mapsto \\
& 0 \\
& \mapsto \\
& z \\
& z
\end{aligned}
$$$$
\mapsto
$$$$
\text { 山 }
$$$$
\mapsto
$$$$
\text { ๓ }
$$

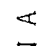

\begin{tabular}{|c|c|c|c|c|c|c|c|c|c|c|c|}
\hline \multirow[b]{2}{*}{$\begin{array}{c}\text { Micrococcus Species } \\
\text { (After Bergey, } \\
\text { 6th Ed.) }\end{array}$} & \multirow[b]{2}{*}{$\begin{array}{l}\text { No. of } \\
\text { Cultures }\end{array}$} & \multicolumn{6}{|c|}{ DETERMTNATIVE } & \multicolumn{2}{|c|}{ REACTIONS } & \multirow[b]{2}{*}{$\begin{array}{l}\text { Anae- } \\
\text { robic } \\
\text { Growth }\end{array}$} & \multirow[b]{2}{*}{$\mathrm{pH}^{1}$} \\
\hline & & $\begin{array}{l}\text { Man- } \\
\text { nitol }\end{array}$ & $\begin{array}{l}\text { Pig- } \\
\text { ment }\end{array}$ & $\begin{array}{c}\mathrm{Gel-} \\
\mathrm{atin}\end{array}$ & $\begin{array}{l}\text { Litmus } \\
\text { Milk } \\
\end{array}$ & $\begin{array}{l}\text { Amm- } \\
\text { onium } \\
\text { Phos- } \\
\text { phate }\end{array}$ & $\begin{array}{l}\mathrm{Ni}- \\
\text { trite }\end{array}$ & M.R. & V.P. & & \\
\hline pyogenes $v$, aureus & 82 & + & orange & + & acid, coag. & - & + & + & + & + & $\begin{array}{c}4.92 \\
(5.20-4.80)\end{array}$ \\
\hline pyogenes v. albus & 91 & + & white & + & acid, coog & - & + & + & + & + & $\begin{array}{c}4.96 \\
(6.50-4.70)\end{array}$ \\
\hline aurantiacus & 24 & + & orange & - & ocid only & - & + & + & + & + & $\begin{array}{c}5.18 \\
(5.72-4.84)\end{array}$ \\
\hline candidus & 23 & \pm & white & - & acid only & - & - & + & + & + & $\begin{array}{c}5.01 \\
(6.03-4.73)\end{array}$ \\
\hline freudenreichii & 10 & \pm & white & + & acid, coag. & + & - & + & - & + & $\begin{array}{c}4.94 \\
(5.77-4.12)\end{array}$ \\
\hline conglomeratus & 5 & \pm & yellow & + & acid only & + & + & - & - & + & $\begin{array}{c}5.40 \\
(6.72-4.92)\end{array}$ \\
\hline caseolyticus & 5 & + & voriable & + & $\begin{array}{r}\text { ocid, coog. } \\
\text { pept. }\end{array}$ & + & - & + & + & + & $\begin{array}{c}5.01 \\
(5.90-4.18)\end{array}$ \\
\hline flavus & 14 & \pm & yellow & + & acid, coag. & + & - & \pm & \pm & + & $\begin{array}{c}4.98 \\
(5.80-4.70)\end{array}$ \\
\hline varians & 1 & + & variable & - & acid, coagt & + & + & - & - & + & 5.02 \\
\hline ureae & 1 & + & white & - & N.C., alk. & + & - & + & + & + & * \\
\hline epidermidis & 7 & - & white & - & acid only & - & + & + & + & + & $\begin{array}{c}4.74 \\
(5.64-4.18) \\
\end{array}$ \\
\hline
\end{tabular}$$
\text { z }
$$$$
\mapsto
$$$$
4
$$

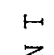


B ACTERIOLOGICAL NOMENCIATURE A N D T A X O N O M Y

TABLE 2

The Production of Acld

Aerobically and under two conditions of anaerobiosis

by representatives of pathogenic and nonpathogenic species of Micrococcus

\begin{tabular}{|c|c|c|c|}
\hline \multirow[b]{2}{*}{ Species } & \multicolumn{3}{|c|}{$\begin{array}{l}\text { pH after standard culture: } \\
\text { a verage and range values }\end{array}$} \\
\hline & Aerobic & $\begin{array}{r}\text { Anaerobic } \\
\text { (Vaspar) }\end{array}$ & $\begin{array}{l}\text { Anaerobic } \\
\text { (Brewer jar) }\end{array}$ \\
\hline M. pyogenes var. aureus & $\begin{array}{c}4.87 \\
(5.10-4.77)\end{array}$ & $\begin{array}{c}4.83 \\
(4.95-4.69)\end{array}$ & $\begin{array}{c}4.71 \\
(4.98-4.53)\end{array}$ \\
\hline M. pyogenes var. albus & $\begin{array}{c}5.15 \\
(5.72-4.80)\end{array}$ & $\begin{array}{c}5.03 \\
(5.38-4.72)\end{array}$ & $\begin{array}{c}5.00 \\
(5.45-4.66)\end{array}$ \\
\hline M. aurantiacus & $\begin{array}{c}5.12 \\
(5.27-4.96)\end{array}$ & $\begin{array}{c}5.26 \\
(5.98-4.93)\end{array}$ & $\begin{array}{c}5.18 \\
(5.72-4.84)\end{array}$ \\
\hline M. freudenreichii & $\begin{array}{c}4.92 \\
(5.27-4.15)\end{array}$ & $\begin{array}{c}4.77 \\
(5.00-4.22)\end{array}$ & $\begin{array}{c}4.94 \\
(5.77-4.12)\end{array}$ \\
\hline$\underline{M}$. candidus & $\begin{array}{c}5.12 \\
(5.55-4.55)\end{array}$ & $\begin{array}{c}5.30 \\
(5.80-4.75)\end{array}$ & $\begin{array}{c}5.34 \\
(6.03-4.73)\end{array}$ \\
\hline M. conglomeratus & $\begin{array}{c}5.88 \\
(7.25-5.10)\end{array}$ & $\begin{array}{c}5.42 \\
(6.89-4.94)\end{array}$ & $\begin{array}{c}5.40 \\
(6.72-4.92)\end{array}$ \\
\hline M. varians & 5.25 & 4.95 & 5.02 \\
\hline M. flavus & $\begin{array}{c}5.20 \\
(5.50-4.80)\end{array}$ & $\begin{array}{c}5.18 \\
(5.80-4.93)\end{array}$ & $\begin{array}{c}5.11 \\
(5.81-4.72)\end{array}$ \\
\hline M. caseolyticus & $\begin{array}{c}5.05 \\
(6.15-4.20)\end{array}$ & $\begin{array}{c}4.90 \\
(5.84-4.28)\end{array}$ & $\begin{array}{c}5.01 \\
(5.90-4.18)\end{array}$ \\
\hline M. epidermidis & $\begin{array}{c}4.74 \\
(5.22-4.20)\end{array}$ & $\begin{array}{c}4.76 \\
(5.61-4.26)\end{array}$ & $\begin{array}{c}4.74 \\
(5.64-4.18)\end{array}$ \\
\hline Control & 6.90 & 6.90 & 6.61 \\
\hline
\end{tabular}


Page 26

I N IER N A I I ONAL B UL LE I I N

was $\underline{M}$. pyogenes. Of 82 representatives of $M$. pyogenes var. aureus, 70 were in the ++ reaction category for both coagulase and phosphatase, 9 were in the respective - + category, and three failed to produce either enzyme. Of the 91 cultures of $\underline{M}$. pyogenes var. albus, 30 were in the ++ category, 39 in the - +, 4 in the +- , and 18 in the - - category. The production of coagulase was confined to the species $\underline{M}$. pyogenes but not as a consistent characteristic of the species since only 60 per cent of the cultures within the two varieties aureus and albus produced this enzyme. Among the aureus cultures, 85 per cent produced coagulase with the corresponding value for the albus cultures being 37 per cent.

Phosphatase was detected not only in cultures of the species $M$. pyogenes but also in the species $M$. aurantiacus, M. candidus, $M$. freudenreichii, $\underline{M}$. caseolyticus, $\underline{M}$. flavus and $\underline{M}$. epidermidis.

The data expressing the production of specific toxins from the 50 cultures randomly selected from the various coagulase-phosphatase categories as described earlier as shown in Table 4. Alpha-lysin was produced consistently by all 23 representatives of the ++ category. Twelve produced alpha and beta lysins and enterotoxin. However, all possible variations for the production of beta lysin and enterotoxin are indicated. Among the 15 cultures in the - + category, 9 failed to produce any of the three toxins, one produced all three toxins, 6 produced enterotoxin. Only one culture in this group produced beta lysin. Only two cultures were found in the + - coagulase-phosphatase category. One produced all three toxins, the other produced none. Among the 10 cultures in the - - category, very low titres of alpha lysin were produced by 4 of them, one produced enterotoxin; one produced beta lysin (titre 1:4) and 6 were without detectable toxins.

The species relationships of this selected group and the phage group to which they belong are indicated in Table 5 together with the toxin production by the representatives of the various species. Clearly, the greatest propensity for the formation of toxins is possessed by the species $M$. pyogenes, but toxins were also produced by representatives of four other species. All representatives of phage group IV produced all three toxins, whereas a wide variation of toxin production is shown by members of phage groups I, II and III. AII strains lysed by the standard phages were members of the species $\underline{M}$. pyogenes, but 10 of 31 isolates of this species were not susceptible to lysis by the phages. Within this "non-typable" group (all of which were coagulase-negative) 
B A C I ER I O L OG I C A L NOMENCLA I URE A N D I A X O N O M Y

TABLE 3

Coagulase and Phosphatase Production

by representatives of various species ${ }^{1}$ of Micrococcus

\begin{tabular}{|c|c|c|c|}
\hline \multirow[t]{2}{*}{ Species } & \multirow{2}{*}{$\begin{array}{l}\text { Number of } \\
\text { Cultures }\end{array}$} & \multicolumn{2}{|c|}{ Reaction Group } \\
\hline & & Coagulase & Phosphatase \\
\hline M. pyogenes var. aureus & $\begin{array}{r}70 \\
9 \\
3\end{array}$ & $\begin{array}{l}+ \\
- \\
-\end{array}$ & $\begin{array}{l}+ \\
+ \\
-\end{array}$ \\
\hline M. pyogenes var. albus & $\begin{array}{r}30 \\
39 \\
4 \\
18\end{array}$ & $\begin{array}{l}+ \\
- \\
+\end{array}$ & $\begin{array}{l}+ \\
+ \\
-\end{array}$ \\
\hline M. aurantiacus & $\begin{array}{r}4 \\
20\end{array}$ & - & + \\
\hline M. candidus & $\begin{array}{r}6 \\
17\end{array}$ & - & + \\
\hline M. freudenreichii & $\begin{array}{l}2 \\
8\end{array}$ & - & + \\
\hline$\underline{M}$. caseolyticus & $\begin{array}{l}1 \\
4\end{array}$ & - & $\begin{array}{l}+ \\
-\end{array}$ \\
\hline M. flavus & $\begin{array}{r}3 \\
11\end{array}$ & - & + \\
\hline M. epidermidis & $\begin{array}{l}3 \\
4\end{array}$ & - & $\begin{array}{l}+ \\
-\end{array}$ \\
\hline
\end{tabular}

'After Bergey, 6th Edition. 
Page 28

I N T E R N A T I O NAL B UL L E T I N

TABLE 4

Specific Toxin Production ${ }^{1}$ by Strains of Micrococcus Coagulase-Phosphatase Reactions

\begin{tabular}{|c|c|c|c|c|c|}
\hline $\begin{array}{l}\text { Number of } \\
\text { Cultures }\end{array}$ & Coagulase & Phosphatase & $\alpha-$ Lysin & $\beta$-Lysin & Enterotoxin ${ }^{3}$ \\
\hline 12 & + & + & + & + & + \\
\hline 7 & + & + & + & - & + \\
\hline 1 & + & + & + & + & - \\
\hline 3 & + & + & + & - & - \\
\hline 1 & - & + & + & + & + \\
\hline 3 & - & + & + & - & + \\
\hline 2 & - & + & - & - & + \\
\hline 9 & - & + & - & - & - \\
\hline 1 & + & - & + & + & + \\
\hline$i$ & + & - & - & - & - \\
\hline 1 & - & - & $+(1: 2)^{2}$ & - & + \\
\hline 1 & - & - & $+(1: 2)$ & $+(1: 4)$ & - \\
\hline 2 & - & - & $+(1: 8)$ & - & - \\
\hline 6 & - & - & - & - & - \\
\hline
\end{tabular}

${ }^{1}$ Toxins determined from cultures randomly selected in accord with the various coagulase-phosphatase reactions.

${ }^{2}$ Maximum titre.

${ }^{3}$ Emesis in cats from intraperitoneal injection of $2 \mathrm{ml}$. filtrate per kilo. 
B A C T ER I OLOG I C A L NOMENCLATURE A $N$ D I A X O N O M Y

TABLE 5

Toxin Production by Selected' Strains of Micrococcus

In relation to species and phage group

\begin{tabular}{|c|c|c|c|c|c|}
\hline Species & $\begin{array}{l}\text { Phage } \\
\text { Group }\end{array}$ & $\begin{array}{l}\text { No. of } \\
\text { Cultures }\end{array}$ & $\alpha$-Lysin & $\beta$-Lysin & Enterotoxin \\
\hline \multirow{15}{*}{$\begin{array}{c}\text { M. pyogenes, } \\
\text { varieties } \\
\underline{\text { aureus and }} \\
\underline{\text { albus }}\end{array}$} & I & 1 & + & + & - \\
\hline & I & 1 & + & - & - \\
\hline & & & & & \\
\hline & II & 1 & + & + & + \\
\hline & II & 1 & + & - & + \\
\hline & III & 2 & + & + & + \\
\hline & III & 1 & + & + & - \\
\hline & II I & 1 & + & - & - \\
\hline & III & 5 & + & - & + \\
\hline & IV & 8 & + & + & + \\
\hline & N.T. ${ }^{2}$ & 1 & + & + & + \\
\hline & N.T. & 2 & + & - & + \\
\hline & N.T. & 5 & - & - & - \\
\hline & N.T. & 1 & - & - & + \\
\hline & N.T. & 1 & + & + & - \\
\hline \multirow[t]{2}{*}{ M. aurantiacus } & N.T. & 1 & +3 & - & + \\
\hline & N.T. & 1 & $t^{3}$ & - & - \\
\hline M. freudenreich11 & N.T. & 1 & $+^{3}$ & - & + \\
\hline M. conglomeratus & N.T. & 1 & +4 & - & - \\
\hline M. epidermidis & N.T. & 1 & - & - & + \\
\hline
\end{tabular}

1 Randomly selected from groups of cultures of different coagulasephosphatase reactions as specified in text.

${ }^{2}$ N.T.--nontypable by standard phages.

${ }^{3}$ Maximum titre--1:4.

${ }^{4}$ Maximum titre--1:8. 
5 cultures produced toxins. The cultures of the remaining species were all coagulase-negative and "non-typable" but included strains that produced alpha lysin at low titre as well as enterotoxin.

\section{DISCUSSION}

The foregoing results point to the marked genetical heterogeneity of the tested cultures of micrococci: a heterogeneity that is expressed in terms of the simple determinative characters, in coagulase and phosphatase production, in specific toxigenicity, phage susceptibility and in interrelationships between these properties.

The key to the genus Micrococcus as listed in the Bergey Manual gives primary significance to the production of pigment and to liquefaction of gelatin in distinguishing between a number of species, while pigment production is the essential difference between the varieties aureus and albus of $M$. pyogenes. While we have not recorded the data in this paper, our experience has been in accord with that of other workers who have found the production of pigment by $M$. pyogenes to be subject to variation with the most common trend being for golden coloured strains of $M$. pyogenes to give rise to colourless or white strains; while it is our belief that the continued growth of certain white strains in a pathogenic environment (as, for instance, when inoculated into the chick embryo) leads on occasion to the development of golden strains. The colour change in this direction has been established also by Barber (2) and by Lack and Wailling (13). Thus, the retention of two varieties of this species on the basis of pigmentation alone seems to be invalid. Comparable reasoning may well apply to the distinction of $\underline{M}$. citreus which differs from $M$. pyogenes in its key characteristics in pigment only, though it is recognized that the expanded description of species in the Bergey Manual offers other distinguishing properties. This applies to other species discussed here.

Similarly, a metabolic change in the ability to liquefy gelatin could also cause interspecific confusion, for if a golden strain of $M$. pyogenes were to lose ability to liquefy gelatin it would then more closely resemble the species M. aurantiacus; while, if the statement of Evans, Bradford 
and Niven ( 8 ) be accepted that growth in ammonium phosphate medium is dependent on the vitamin content of the inoculum, then change in gelatin response in an albus variant of $\underline{M}$. pyogenes would render it subject to classification as M. varians.

The data in this paper establish that neither the MR-VP reactions of Gupta and Chakravarti nor the anaerobic production of acid from glucose are exclusively related to groups of cultures with distinct homogeneity. Instead these properties are to be found among representatives of several species as presently defined, while neither reaction is related dependably to toxin production, which, in turn, is not a restrictive function of those strains that produce either coagulase or phosphatase.

The authors are perplexed by the conclusion of Evans et al. (8) that, "The genera Micrococcus and Staphylococcus can be separated logically on the basis of their relation to oxygen in a standard complex medium containing glucose", for Table 1 of their paper shows that while $\mathrm{M}$. pyogenes (85320) produces acid to provide a final $\mathrm{pH}$ of 5.6 under aerobic conditions and $\mathrm{pH} 5.0$ anaerobically, M. caseolyticus produces acid to provide a final pH of 5.0 under both conditions, M. epidermidis provides the respective values of $\mathrm{pH} 5.3$, and 5.1 , and $M$. candidus 4.6 and 4.3 . Our data on acid production by these same species are in close accord with those of Evans et al.: average pH after anaerobic incubation for 82 cultures of $\mathrm{M}$. pyogenes var. aureus was 4.92; for 91 cultures of $M$. pyogenes var. albus, 4.96; for 23 cultures of $M$. candidus, 5.01 ; for 5 cultures of $M$. caseolyticus, 5.01 ; and for 7 cultures of $M$. epidermidis, 4.74 . Variation in the capacity to produce acid is also apparent within a species, as shown by a final $\mathrm{pH}$ range for $M$. pyogenes of 6.50 to 4.70 . Consistency in interpretation of the suggestion of Evans et al. would seem to require that the three species last named be included in the genus Staphylococcus. But each of these three species is considered to be normally nonpathogenic. Further, our data show that certain strains of other nonpathogenic species are able to grow and to produce acid from the test medium under anaerobic conditions. We find it difficult to see any advantage in establishing a new genus which would need to include strains of at least the ten species listed in Table 1 and which would fail to provide any better recognition of pathogens than at present available. 
The coagulase reaction is a useful exploratory indicator of toxigenicity and seems to be limited to the present species $M$. pyogenes, but not all isolates of this species as currently defined are coagulase-positive. Nelther is toxigenicity a property of all members of $M$. pyogenes nor even of its coagulase-positive representatives. In particular, we have recorded enterotoxin from coagulase-negative strains and from a number of other so-called species. This would be in accord with the work of Haynes and Hucker (11), and is further supported by our observation (16) that a sub-culture of an "albus" variant $(12069, \alpha)$ originally isolated by Dolman from a former golden strain of $M$. pyogenes var. aureus that had been implicated in an episode of food poisoning is now, after several years of culture, coagulase-negative, colourless, nontypable by phage but still produces its characteristic toxin pattern, viz. alpha lysin but no beta lysin and enterotoxin. We have also noticed (16) that certain cultures have been coagulase-negative for as many as three tests conducted shortly after isolation from clinical material, but after a number of sub-cultures on an agar medium have developed the capacity to produce coagulase and have been phage-typable. Two such strains were shown to cause emesis in monkeys. 1

In our hands the production of phosphatase has been a less reliable indicator of toxigenicity of a given strain than is the formation of coagulase. Phosphatase was detected among five species not usually considered pathogenic and was frequently produced in the absence of either of the three toxins for which tests were made.

The phage determinations from the selected group of cultures described in this work show a striking consistence by members of phage group IV in the production of all three toxins. Further, this group in general produces toxins at titres higher than for other phage groups. Within the experience of this laboratory a member of phage group IV has never been found which did not produce a high titre of lysins. Further, the only variant factor we have encountered among this group has been in pigment production. Biochemically determined properties have seemed to be stable to a marked degree.

\footnotetext{
Through the courtesy of Dr. C. E. Evans, American Meat Institute, Chicago.
} 
B A C I ER IOLOGICA L NOMENCLATURE A N D I A X O N O M Y

These last observations are pertinent to a decision of Cowan, Shaw and Williams (7) to reverse a proposal of Shaw, Stitt and Cowan (15) that strain F.D.A. 209 P be considered as the "neotype" or "type strain" for a proposed species Staphylococcus aureus. The earlier proposal was changed because strain F.D.A. $209 \mathrm{P}$ was found to be lysed by phage $42 \mathrm{D}$ and therefore a member of Group IV, considered to be of bovine origin. The data reported in this present paper seem to warrant the suggestion that a decision on this basis should be re-examined, because members of Group IV, due to their marked constancy of determinative characters and of multiple production of toxins might well be more truly a parental "clone" and genetically more suitable as a source of an arbitrarily selected neotype strain from which others may show varying degrees of change. A wide range of variance is particularly evident among members of phage group III from which the newly proposed neotype has been chosen, the choice being based upon the numerical preponderance of Group III among clinical specimens.

\section{GENERAL CONCLUSIONS}

Based on the observations expressed above and in response to the request of the Editorial Board of this Bulletin (1) the following recommendations are offered:

1. Postulation of the two genera Micrococcus and Staphylococcus is not yet warranted on a taxonomic basis because, at present, no scheme of consistent determinative properties of micrococci has been described for positive recognition of distinctive groups of generic rank. The evidence points to pronounced genetical heterogeneity among the cocci under discussion.

2. Variation in pigment production, being on occasion reversible, offers a dubious basis for taxonomic distinction between varleties of the species $\underline{M}$. pyogenes.

3. If it be deemed desirable to separate pathogens from nonpathogens and to establish two genera by arbitrary postulation, then a majority of pathogens may be recognized on the basis of susceptibility to standard phages which at 
present seems to be limited to coagulase-positive strains. However, neither the coagulase reaction nor phage susceptibility seems to be an absolute criterion of distinction for toxigenic strains, and the latter property has practical objections in that it involves procedures not widely available to the smaller laboratories; while if coagulase-production were adopted as a primary specific character this would result in exclusion from the proposed species, $\underline{S}$. pyogenes, several strains that are $M$. pyogenes by present criteria.

If phage susceptibility were to be considered as a determinative factor in any such arbitrary segregation of strains then choice of a member of a highly variable group (Group III) as a neotype seems inadvisable when some acceptance already has been extended to a well-defined and widely distributed member of a group that seems to be genetically more stable and is consistently productive of known toxins. If this argument be accepted, then strain F.D.A. 209 P would constitute a preferable neotype as compared with strain $S 33 R_{4}$, even though the former is a representative of a phage group most commonly encountered among bovines and dairy products.

4. The demonstrated heterogeneity among the micrococci leads to a concept of a group of strains of bacteria whose differing representatives possess a high degree of "overlapping" of characters and among which transitional, and to some extent genetically unstable, forms make species differentiation more than usually arbitraxy. Restudy of existing schemes for distinguishing species seems desirable in the light of such a concept, an evaluation which seems to parallel the suggestion of Barber (2).

\section{REFERENCES}

1. Anonymous. The bacterial generic names Micrococcus and Staphylococcus. Preliminary Statement. The Editorial Board. Internatl. Bull. Bact. Nomen, and Taxon. 4 (3): 163-166. 1954.

2. Barber, M. Pigment production by Staphylococci. Jour. Gen. Microbiol. 13:338-345. 1955. 
B A C T ERIOLOGICAI NOMENCLATURE A N D I A X O N O M Y

3. Barber, M. and S. W. A. Kuper. Identification of Staphylococcus pyogenes by the phosphatase reaction. Jour. Path. and Bact. 63 (1):65-68. 1951.

4. Breed, R. S. Staphylococcus pyogenes Rosenbach. Internat 1. Bull. Bact. Nomen. and Taxon. 6 (1):35-42. 1956.

5. E. G. D. Murray and A. P. Hitchens. Bergey's Manual of Determinative Bacteriology. 6th Ed. The Williams and Wilkins Co., Baltimore. 1948.

6. Carrere, L., and J. Roux. Activité phosphatasique des Staphylocoques. Ann. de l'Inst. pasteur 87 (3):349. September 1954.

7. Cowan, S. T., C. Shaw and R. E. O. Williams. Type strain for Staphylococcus aureus Rosenbach. Jour. Gen. Microbiol. 10 (1):174-176. 1954.

8. Evans, J. B., W. L. Bradford and C. R. Niven. Comments concerning the taxonomy of the genera Micrococcus and Staphylococcus. Internatl. Bull. Bact. Nomen. and Taxon. 5 (2):61-66. 1955.

9. Gibson, T. The status of the generic names Micrococcus and Staphylococcus and of the species name Staphylococcus aureus. Internatl. Bull. Bact. Nomen. and Taxon. 3 (2):129-133. 1953.

10. Gupta, S. P. and R. N. Chakravarti. Observations on some biochemical reactions of Staphylococci, with special reference to coagulase and phosphatase production. Indian Jour. Med. Res. 42 (1):131-134. 1954.

11. Haynes, W. C. and G. J. Hucker. Studies on the Coccaceae XVIII. The enterotoxin-producing micrococci. New York State Agric. Exp. Sta. Tech. Bull. 275:1-82. 1945.

12. Hucker, G. T. Studies on the Coccaceae IV. The classification of the genus Micrococcus Cohn. New York State Agric. Exp. Sta. Tech. Bull. 102:1-46. 1924.

13. Lack, C. H. and D. G. Wailling. A study of 435 strains of Staphylococcus pyogenes with reference to factors which may contribute to pathogenicity. Jour. Path. and Bact. 68 (2):431-442. 1954 .

14. Manual of methods for pure culture study of bacteria. Biotech. Publications, Geneva, New York. 1946.

15. Shaw, C., J. M. Stitt and S. T. Cowan. Staphylococci and their classification. Jour. Gen. Microbiol. 5: 1010-1023. 1951. 
Page 36

I N TERNAIIONAL BULLETIN

16. Thatcher, F. S. and W. Simon. A comparative appraisal of the properties of staphylococci isolated from clinical sites and from dairy products. Canadian Jour. Microbiol. In press.

17. Van Eseltine, W. P. On the inadvisability of separating the genera Micrococcus and Staphylococcus. Internatl. Bull. Bact. Nomen. and Taxon. 5 (2):53-60. 1955. 